\title{
Market Diffusion of Second-life Electric Vehicle Batteries: Barriers and Enablers
}

\author{
Na Jiao ${ }^{1}$, Steve Evans ${ }^{2}$ \\ ${ }^{1}$ Institute for Manufacturing, University of Cambridge, 17 Charles Babbage Road, Cambridge, CB3 OFS, UK \\ nj268@cam.ac.uk
}

\begin{abstract}
Summary
Repurposing retired electric vehicle (EV) batteries provides a potential way to reduce EV cost hurdles. Embedded in energy storage systems, second-life EV batteries could unlock the energy storage market and generate synergic value for the energy sector. From case studies with various stakeholders, this paper presents key factors that impact the market development for second-life batteries and explains why some stakeholders are more capable for the market diffusion. The results provide practical implications for both industrial players and policy makers.
\end{abstract}

Keywords: electric vehicle, second-life battery, energy storage, market, case-study

\section{Introduction}

Over the last few decades, global concerns over climate change and energy security have strengthened the interest in developing electric vehicles (EVs) to decarbonise the transport sector [1]. Despite policy support, the affordability of EVs is still considered to be one of the biggest challenges that impede EV market penetration. Currently, battery constitutes the single largest cost items for EVs [2]. Maximising the value of batteries through further extending their lifetime in second-use applications could help bring down either the battery cost for EV manufacturers or the total cost of ownership (TCO) for EV customers.

An EV battery reaches its end-of-life (EOL) in vehicle service, and replacement is recommended, when its remaining capacity is below $70-80 \%$ of a new one in order to satisfy the driving range demand of EV owners[3]. Upon retirement, there would still be sufficient capacity left to support less demanding applications such as load shifting, renewable energy storage, back-up power, etc. [3-5]. Further, battery second use (B2U) could postpone the recycling phase which entails cost and waste. Repurposing retired batteries for second-life applications extends their total service life, which in turn increases EV value. Recapturing this remained value could generate alternative revenue streams to overcome EV cost-hurdles and create synergic value for the energy storage market.

Various automotive companies have initiated demonstration projects in collaboration with energy companies and governments to investigate the viability of B2U. From case studies with major players in the B2U market, we observe key determining factors for B2U and investigate their impacts on shaping the ecosystem around second-life batteries. Our analysis shows that in the nascent stage of B2U, a standardized platform, inter-industrial collaboration and regulatory support constitute the most important factors for B2U market development. Cost of new batteries in the future presents a major challenge for B2U, which makes it essential to get second-life batteries ahead of the curve and establish the infrastructures for B2U. The EV manufacturer is the key player in developing the B2U market in the nascent ecosystem and innovative business models are essential in enabling second-life batteries to compete in the energy storage market. 


\section{Literature Review}

The idea of B2U is not new to the industry, and the benefits and concerns are widely discussed in various industrial reports and literature [5-7]. Investigations into B2U are mostly motivated by the potential profits generated from second-life batteries to reduce the capital cost of EVs. The first published study was Argonne National Laboratory's "Electric vehicle battery 2nd use study" conducted for the United States Advanced Battery Consortium (USABC) in 1998 [8]. This study demonstrated competitive performance of used automotive NiMH batteries compared to new lead-acid batteries in several stationary applications. After that, a study by Cready et al. investigated the technical and economic feasibility of applying used NiMH EV batteries in stationary applications and "did not come across any insurmountable technical barriers to the implementation of a second use scheme" [3]. This report also indicated several important issues to be addressed: the standardization of battery modules, the mechanism of applying B2U value to EV owners, the warranty terms and costs, and perceived value of used batteries compared to new batteries in customers' minds. Although several studies on B2U have been existed for a while, there was no large-scale commercialisation of second-life batteries because of low EV penetration.

Significant development of EV since the last decade and advances in battery technology from NiMH to Liion has reignited interest in B2U as a strategy for overcoming EV cost hurdles [9]. This has motivated substantial published studies that look into B2U from various perspectives. Based on previous research on $\mathrm{NiMH}$ batteries, studies have been refined to include investigating technical and economic feasibility of B2U in various stationary applications [5,7,10-16], quantifying the effect of B2U on EV cost reductions [17], development of frameworks/tools to determine optimum operating conditions to maximize battery value [2,18], analysing the environmental feasibility of second-life batteries [19] and so on. These studies show that although most B2U strategies are viable in terms of battery performance and economics, there are uncertainties in battery degradation and new battery price reduction. Most of these studies are quantitative and require a detailed breakdown of technical, economic or environmental parameters of each process. Due to the complexity and uncertainty of parameters during the early stage of B2U market, these studies tend to be limited in certain boundary conditions and estimate assumptions [20].

J. Neubauer et al. from the National Renewable Energy Laboratory (NREL) did a comprehensive work on B2U from predicting battery degradation and availability for second use, illustrating repurposing procedures and calculating repurposing cost, to evaluating the potential markets for second-life batteries [9]. Critical barriers were identified and recommendations for major B2U stakeholders were made. It was suggested that although B2U has little ability to reduce EV upfront cost, the overall benefits to society can be quite large, which should be recognized and valued. Apart from that, little work has been done so far to comprehensively study the secondary use of EV batteries as a new market. The B2U market is unique due to its involvement of both the automotive and electric power industry which have little overlap before, along with other essential stakeholders such as the government. And at this embryonic stage of the B2U ecosystem that is plagued with uncertainties, qualitative research tends to take a wider and inclusive view on potentials related to second-life batteries. In this paper, the authors take a multi-stakeholder perspective on a system level and collect the expertise through case studies with various stakeholders in the B2U ecosystem. Barriers and enablers that impact the market development of second-life batteries are investigated and their implications for both industrial practitioners and policy makers are studied.

\section{Research Method}

Due to the nascent and complex nature of the research context, a qualitative case study method is adopted to provide a contextual understanding of the research topic [21]. Qualitative research isn't limited by the requirement to quantify every parameter, so it tends to take a wider perspective for potentials related to the B2U context. Case studies from Japan, USA and China are selected on the basis of their high EV penetration and strong interests in energy storage and B2U strategies. Based on their different roles of stakeholder in both the automobile and energy sectors, the cases depict an inchoate picture of the B2U ecosystem. Qualitative data are collected through semi-structured interviews with CEOs and managers across various sectors. For this early-stage market, interviews with various stakeholders provide a rich source of information and a comprehensive understanding of the factors that might form the market mechanism. The stakeholders selected for the case studies are: battery producer, EV manufacturer, B2U joint venture and energy company (table 1). From case studies with global companies, we aim to present a systematic map that will help stakeholders reflect on this emerging market and make joint efforts to facilitate the development of B2U. 
Table 1: B2U case studies

\begin{tabular}{|c|c|c|c|l|}
\hline $\begin{array}{c}\text { Case } \\
\text { No. }\end{array}$ & $\begin{array}{c}\text { Company/ } \\
\text { Joint Venture }\end{array}$ & Region & $\begin{array}{c}\text { Role of } \\
\text { Stakeholder }\end{array}$ & \multicolumn{1}{|c|}{ Strategy \& Capability } \\
\hline 1 & Company A & China & $\begin{array}{c}\text { Battery \& } \\
\text { EV manufacturer }\end{array}$ & $\begin{array}{l}\text { Collaboration with electricity suppliers; } \\
\text { EV fleet (taxies and buses); technology } \\
\text { leadership for batteries }\end{array}$ \\
\hline 2 & Company B & Japan & $\begin{array}{c}\text { EV manufacturer } \\
\text { (OEM) }\end{array}$ & $\begin{array}{l}\text { Establishing a B2U joint venture to } \\
\text { support the EV programme; leadership } \\
\text { for EV sales }\end{array}$ \\
\hline 3 & Joint Venture C & Japan & B2U utility & $\begin{array}{l}\text { Partnership with energy storage } \\
\text { companies; support from OEM; } \\
\text { expertise in B2U }\end{array}$ \\
\hline 4 & Company D & California & $\begin{array}{c}\text { Energy storage } \\
\text { service provider }\end{array}$ & $\begin{array}{l}\text { Niche market in low-cost mobile EV } \\
\text { charging service for commercial utilities } \\
\text { to avoid expensive construction project. }\end{array}$ \\
\hline
\end{tabular}

\section{Case Study}

This section presents the B2U context and case description (section 4.1 and section 4.2), followed by the analysis of the case studies (section 4.3). There are few commercialization cases for B2U due to limited volume of retired EV batteries in the market, but all three regions (California, Japan and China) strongly support EV development and try to seek for their convergence with energy storage through utilization of EV battery either during vehicle service (e.g. vehicle to grid) or upon end-of-life in cars (e.g. battery secondary use). On-going activities include partnerships between major stakeholders, pilot and demonstration projects and small-scale commercial activities. The barriers to and enablers of B2U for each of the cases are explained through single-case analysis, and then the key determining factors for the B2U ecosystem development are analysed through cross-case analysis.

\subsection{Context}

Significant advances in battery technologies have reignited the enthusiasm for EVs as a promising alternative for gasoline cars to decarbonize the transport sector. Many countries have set ambitious targets for EV sales and provided incentives and facilitating measures at both national and regional level. For example, the Zero Emission Vehicles (ZEV) Mandate in California requires OEMs to produce a certain percentage of ZEVs for sale and anticipates a 1.5 million ZEVs on the road by 2025 [22]. Japan has the second largest number of EVs owned in the world just behind the US. The 2014 Automobile Industry Strategy sets goals for the ratio of EVs at $15-20 \%$ in 2020 and $20-30 \%$ in 2030 and the Ministry of Economy, Trade and Industry (METI) has been endeavouring to promote EV penetration through subsidy programme and projects for facilitating the charging infrastructure [23]. In China, the development of EVs has been listed among the key pillar of the automotive industry strategies and in 2009, the government carried out the "Ten Cities, One Thousand Cars" programme to support pilot projects to subsidize EVs in the transportation system.

However, battery cost, which constitutes the single largest cost item of an EV, still remains high. Despite policy support, EVs must find a way to self-sustain, especially when the subsidies from the government gradually diminish. On the one hand, OEMs are improving battery technology and scaling up battery production to reduce the cost of batteries. Meanwhile, many OEMs are considering various means to extract more value from batteries, one of which is to generate alternative revenues throughout extended battery life when they fail to satisfy onboard service demands. Second-life batteries with insufficient capacity for EVs can be used to support less demanding energy storage applications, which provides a promising solution to the current expensive battery storage systems. With the increasing integration of renewable energies, efficient and economical storage systems are demanded to improve the efficiency of integration and the stability of the grid. 


\title{
4.2 Case Description
}

\author{
Case 1\# Company A (China)
}

Company A is a key battery producer and car company in Shenzhen, China founded in 1995. The company initially started as a mobile phone battery producer and has become one of the world's largest rechargeable battery manufacturers. Besides, they also have expertise in the IT and energy storage sectors. Company A stepped into the automobile industry in 2003 when it created a subsidiary to produce conventional vehicles. Based on its advanced battery technology and automobile production capability, company A launched their first EV in 2010 and has become a key player in the Chinese EV industry.

Case 2\# Company B (Japan)

Company B is a Japanese multinational automobile manufacturer headquartered in Yokohama, Japan. Since 1999, company B has been part of the alliance with a French automaker. Taken together, the alliance was the world's fourth largest automaker in 2013. Company B introduced their $100 \%$ EVs since 2010 as the first mass-market, all electric car launched globally. Being the world's best-selling EV, company B is by far the only automaker whose global sales has exceeded 200,000 units. Through its Zero-Emission Programme, company B tries to deliver the holistic approach to achieve "zero" from promoting the development and production of battery and EVs and the construction of infrastructure (e.g. charging infrastructure and standards) to smart grid research and charging network development, battery secondary use and collaborations with government.

Case 3\# Joint venture C (Japan)

Joint Venture C is a joint effort between company B and Sumitomo in Yokohama, Japan. Joint Venture C was established in 2010, earlier than the official launch of the EV of company B. Joint Venture $\mathrm{C}$ has been making efforts to address the technical issues related to $\mathrm{B} 2 \mathrm{U}$ and running demonstration projects to test the technical viability of reusing second-life batteries under various energy storage scenarios. Meanwhile, they have been studying the energy storage market and trying to understand potential customers using new EV batteries due to the limited volume of retired EV batteries. They have also run pilot projects in collaboration with energy companies to try out business models for innovative storage solutions.

Case 4\# Company D (California)

Company D is a start-up developing battery-based energy delivery and storage solutions in California, USA. Being the first to commercially deploy second-life EV batteries, company D was established in 2014 and launched their first product in 2015 using second-life EV batteries. This product was built to solve the pain point - expensive EV charging construction projects for utilities who are considering to scale up EV charging infrastructure. It is the first solution to combine EV charging with grid-level energy management by creating a network of grid-smart mobile EV chargers and providing charging service using second-life batteries. Their second product will be a mobile energy storage system with second-life battery on board with the aim of replacing current diesel generators. The business as a whole is to create energy storage systems to address the pain points in niche markets.

\subsection{Case Analysis}

\subsubsection{Battery and EV manufacturer - Company A (China)}

Since 2005, company A has released 6 EV models including electric buses, pure electric hatchbacks and hybrid EVs. The pure electric city bus model has a range of $250 \mathrm{~km}$. It has been successfully operated in several cities both in China and abroad. The hybrid model is a dual mode plug-in hybrid electric car with a range of $60 \mathrm{~km}$ under pure EV mode. The pure electric hatchback has a maximum range of $400 \mathrm{~km}$ per charge. This five-door model is widely used as taxi fleets through a demonstration project in Shenzhen, China. In addition to being a key player in the Chinese EV industry, company A is also active in the energy sector. They have been producing solar cells that have been used in photovoltaic stations, street lamps etc. As part of their new energy strategy, they have also been devoted to energy storage stations using their lithium-ion batteries to reduce electricity load fluctuations.

The National Development and Reform Commission in China is leading the B2U policy formulation for two purposes: one is to reduce the environmental burden from large-volume disposed lithium batteries; the other is to regulate the B2U market to help EV manufacturers reduce cost and promote EV adoption. As a 
battery as well as an EV manufacturer, company A plays an important role in the B2U market. According to company A, B2U is something they must consider in order to sustain themselves as the subsidy from government gradually declines. Supported by their large database and expertise in batteries, company A is able to test battery conditions upon end-of-life on board and make predictions in battery degradation during their second-life applications. They have run several pilot projects in collaboration with National Grid to demonstrate the viability of applying second-life batteries in energy storage systems and no insurmountable technical obstacles to B2U were identified in the demonstration. However, in this nascent stage of B2U, there are many barriers that need to be addressed in order for the successful commercialization of secondlife EV batteries in the market. According to company A, one of the most critical barriers to B2U is customers' bias towards used batteries in terms of safety and performance. It is expected that government should take the lead and work with research institutions as well as major OEMs to provide demonstration and guidance to reassure customers. Government has taken measures trying to regulate the B2U market, e.g. the extended producer responsibility (EPR) stipulates that EV manufactures are responsible for end-of-life EV batteries. Although the EPR system could motivate EV manufactures to take B2U seriously to some extent, detailed regulation such as market standardization and B2U liability should be provided to start B2U mechanism in practice. In addition, B2U stakeholders should work in joint effort to establish the infrastructure for $\mathrm{B} 2 \mathrm{U}$, e.g. professional dismantling companies and logistics.

\subsubsection{EV manufacturer - Company B}

The Zero-Emission Programme of company B aims to deliver the concept of "zero" through a holistic approach to mass-market their zero-emission vehicles. Since 2010, they have sold more than 200,000 units of EVs globally, which is regarded as one of the most successful EV commercialization stories. Apart from selling EVs, company B has also been involved in various activities to support the EV programme. Taking a comprehensive approach and a life-cycle perspective, they have been endeavouring to produce highquality and safe EVs, promote the construction of charging infrastructure and standards, decarbonize charging sources by renewable-integrated charging, facilitate smart-grid advancement through research in vehicle to grid (V2G) and vehicle to home (V2H), address end-of-life issues such as battery secondary use and collaborate with governments. They established a B2U joint venture in 2010 to specifically deal with second-life batteries, before the launch of their first EV. The motivations for this effort are, most importantly, to support the holistic approach of the EV programme. In addition, alternative revenue streams are expected from extending the lifetime of EV batteries and extracting value from energy storage applications. The electricity liberalization in Japan from 2016 will generate a huge market demand for battery storage, where second-life batteries could have a place before recycling or disposal. This electricity reform, according to company B, is regarded as one of the key opportunities for the B2U business in Japan. For company B, they have many advantages in getting a head start in the B2U market. First of all, they started launching EVs from 2010 and by now, they already have a certain amount of retired EV batteries e.g. from taxi fleets that they can experiment with. Besides, they have the large database from their global data centre to run test and predictions about battery life and performance. And their well-engineered, robust batteries designed for EVs could still outperform new lead-acid batteries in energy storage even if they are second-life batteries. The key is the cost of repurposing those second-life batteries compared with new battery prices. With the price of new batteries dropping steeply, the challenge from new batteries is considered to be the most important barriers to B2U for company B.

\subsubsection{B2U utility - Joint venture C}

Joint venture $\mathrm{C}$ was established in 2010 to deal with second-life batteries retired from EVs. For the first two years when the volume of retired EV batteries was limited, they did market research and entered the market with new batteries the same as the EV battery modules. During the second stage where they are now, joint venture $\mathrm{C}$ is expanding and keeping learning the market by selling new battery products. With certain amount of batteries retired from EVs, they also start B2U development to understand the market and customers, but mainly in the form of testing, demonstration and pilot business. They have done the technical feasibility study at both pack and module level. With support from the OEM's technical team and access to their global data centre, joint venture $\mathrm{C}$ has established a simulation system to measure battery deterioration and make predictions on the remained life of second-life batteries. Apart from technical studies, they are also testing a business model in a demonstration project using second-life EV batteries in collaboration with a power producer and supplier (PPS) in Japan. The business model is to provide peakshaving service to customers with no up-front cost to reduce energy bills and share the savings. Joint venture $\mathrm{C}$ provides the energy storage systems comprised of second-life batteries for free while the PPS 
provides the energy storage and management services. Then joint venture $\mathrm{C}$ and the PPS share the savings in energy bills with the customer. For joint venture $\mathrm{C}$, the estimated payback time is 5 years, which means not only the cost of repurposing but that the total cost of system should be reduced to shorten the payback period. Meanwhile, the fierce competition from increasingly cheaper new batteries could pose a great challenge for B2U business. According to joint venture C, they "should keep the cost benefit of used batteries, not forever, but for the time" to establish the market and get customers used to second-life batteries. Thus, they want to start the B2U business earlier to keep more advantage and reassure customers of second-life batteries. With several years' exploration and experience with second-life batteries, joint venture $\mathrm{C}$ expects to commercialize second-life EV batteries from 2016 and start the full-scale B2U business from 2019.

\subsubsection{Energy storage service provider - Company D}

Company D is a start-up founded in California in 2014 that creates energy storage systems to solve the pain points in niche markets. They started when they saw the problem in EV charging - the high cost of charging infrastructure and the under-utilization of charging stations. To solve this problem, company D builds the mobile charging system using second-life EV batteries and provides mobile charging services to utilities. They went to the market using second-life batteries for two reasons: first, second-life batteries were much cheaper than new batteries for the time; second, they created a market for end-of-life EV batteries, which could help automobile companies to sell their EVs. And this could make OEMs more willing to do business with them. It is, actually, the first commercialization of B2U in the world and the first solution to combine EV charging with grid-level energy management by creating a network of gridsmart mobile EV chargers. With the flexibility to easily scale up and built-in energy management platform, this mobile charging solution allows customers to avoid expensive and tedious construction project for charging infrastructure and optimize electricity bills for EV charging.

Despite the initial success, company D sees many challenges facing second-life EV batteries. As new battery price going down rapidly, the cost advantage of second-life batteries would be small and the B2U market could be greatly limited in the future. From the perspective of company D, the main barriers that might keep them away from second-life batteries actually come from the OEMs. For the time being, there is no standardization platform for B2U, which makes them undertake more risks in B2U businesses. First of all, those batteries are designed for EVs and might change (e.g. chemistry, form factor) with the evolvement of EV iteration. The lack of standardized products puts on more uncertainties of the system built around the batteries. Besides, there is currently no standardized pricing on second-life batteries. More transparency on battery pricing is expected to make second-life battery more acceptable to customers. In addition, the contract in B2U is not standardized, which also adds on uncertainties for companies that use second-life batteries. For company D, it is very important that OEMs should work in collaboration with energy companies like them to make the B2U market more standardized and transparent.

The regulatory environment in California is also a key factor for the B2U development. Regulators such as the California Energy Commission are very supportive of EVs and battery storage. In California, there is an incentive programme that subsidizes the cost of new batteries (not including second-life batteries) for commercial storage systems, which could become one of the challenges for B2U. Thus, OEMs as well as energy companies considering B2U business should make joint efforts to change this situation for secondlife batteries on the policy side.

\subsection{Cross-case Analysis}

The nascent B2U ecosystem has been emerging and the enablers of and barriers to the B2U market development have been analysed through case studies with four key stakeholders within the ecosystem. Our case study results indicate that technical issues related to second-life batteries are less a concern to B2U stakeholders. However, companies with better dataset regarding battery use history are more capable to validate the performance and safety of second-life batteries and thus, get a head start in the B2U business. For company A and company B (battery and EV manufacturers), they both have expertise in EV batteries and large database support from their data centres that enable them to make B2U strategies. For joint venture C (B2U utility), they are able to test battery condition and predict second-life battery performance in that they have access to the OEM's database. Company D is the customer in the B2U ecosystem and they also run substantial tests that also validate the technical feasibility of B2U. 
The price of new batteries is considered to be one of the most critical challenges for the B2U market. With technology improvements and increased plant capacity of battery manufacturers, the cost benefit of secondlife batteries is likely to be limited. All of the stakeholders in the case studies indicate that the competition from new batteries constitutes a huge barrier to the B2U market. For company D (energy company), the customer of second-life batteries, this cost competition from new batteries would make them more demanding on second-life batteries. Thus, it is very important for B2U stakeholders to enter the market earlier when there is cost advantage of second-life batteries and establish necessary infrastructures to facilitate B2U diffusion. Meanwhile, it is essential for B2U stakeholders to explore innovative business models that make second-life batteries more attractive to customers, e.g. the service-based business models developed by joint venture $\mathrm{C}$ and company $\mathrm{D}$ that reduce the risks in battery cost and performance on customers.

From our analysis, it is very likely that B2U would become a demand-driven market where products and services are offered on the basis of the demands from customers. From the customer's perspective (company D), a standardized platform for second-life batteries that reduces the risks on their business is a very important factor driving them for second-life batteries rather than new batteries. In this sense, OEMs should collaborate with key B2U stakeholders such as governments, other major OEMs, B2U utilities and customers to make joint efforts in standardizing their products, pricing and contract.

In summary, our case studies with key B2U stakeholders show that B2U is technically feasible. OEMs and B2U utilities with better dataset are more capable to get a head start in the B2U market. The competition from new battery price is considered to be the most critical challenge for B2U development. To keep more advantages of second-life batteries, B2U stakeholders should establish the market and build infrastructures for B2U earlier. In addition, innovative business models are essential in making second-life batteries more attractive. It is expected that the B2U market would be demand-driven and at this nascent stage of B2U ecosystem, a standardized platform, inter-industrial collaboration and regulatory support are the key determining factors for the market diffusion of second-life batteries.

\section{Discussion}

\subsection{Role of OEMs in B2U}

In this paper, the OEM is the EV manufacturer. From the case studies with key B2U stakeholders, our results indicate that the EV manufacturer is the key player in developing the B2U market in the nascent stage. The main driver for automobile companies to repurpose retired EV batteries is to support their EV programme. Through extending the lifetime of EV batteries into secondary applications, more value from batteries could be extracted and alternative revenue streams could be generated to reduce the upfront cost of EVs. And in many countries, OEMs are responsible for end-of-life EV batteries, which entails costs in terms of transportation, storage and testing of retired batteries. By creating a B2U market to introduce those batteries into other applications, OEMs are not only increasing the value of their EVs but also postponing the cost of battery end-of-life treatment. For B2U customers, they use second-life batteries because they are cheaper than new batteries and could achieve the performance they need for their systems. However, the customers could easily go for new batteries if the cost advantage of second-life batteries disappears. As a result, it is crucial that OEMs establish the B2U market mechanism early and come up with innovative business models that make second-life batteries attractive. Besides, OEMs holds the key to battery design and control strategies. To maximize the battery value throughout its lifetime, they should take B2U into consideration when they initially design the batteries for EVs.

In the previous section (Section 4.4), we analysed the determining factors for B2U development: a standardized platform, inter-industrial collaboration and regulatory support. In the emerging stage of B2U, OEMs play an important role in enabling the determining factors to facilitate B2U ecosystem development. To form a standardized platform, OEMs should firstly, standardize their products and guarantee steady supply for customers. Second-life battery pricing mechanism should be established and battery price to customers should be standardized to ensure market transparency. To have a proper contract with customers, OEMs should work with customers as well as other stakeholders in the B2U ecosystem to establish a standardized contract for second-life batteries and warranty terms to assure customers. As a newly emerged ecosystem, B2U entails substantial collaborations among stakeholders to leverage ecosystem resources and establish the value chain and B2U infrastructures to support the ecosystem. Holding the upstream value chain, OEMs should take the lead to work in collaborations with extent players and potential B2U 
stakeholders. In addition, regulatory support e.g. financial subsidies and market regulations is crucial for the development of B2U system in the early stage. OEMs should make joint efforts with other ecosystem players to negotiate with the governments in terms of financial as well as policy support for second-life batteries to regulate and promote B2U market development.

\subsection{Recommendations}

In this section, we propose 3 recommendations to provide insights into overcoming the barriers to $\mathrm{B} 2 \mathrm{U}$ market diffusion for B2U ecosystem players:

- Collaboration with battery manufacturers to avoid competition from new batteries

- An innovative business model to reduce risks on customers

- Joint efforts from regulators, major OEMs and research institutes to establish standards and demonstrations and educate customers

\subsubsection{Collaboration with battery manufacturers}

The competition from new batteries is considered to be the most critical barrier that could limit B2U market diffusion. With new battery price declining rapidly, it will be increasingly difficult for second-life batteries to compete in the battery market. The advantage of second-life batteries would disappear completely if new battery prices drop to the same level as the cost to repurpose second-life batteries. And the interesting point is that battery manufacturers who are now suppliers to EV companies might become competitors to OEMs in the B2U market. It is thus unwise to push second-life batteries onto the market and directly compete with new batteries. On the contrary, B2U players could join hands with battery manufacturers to build mechanisms that could benefit both new and second-life batteries.

\subsubsection{Innovative business models}

Unlike new batteries that mainly compete on technical merits and cost, the success of second-life batteries depends more on the business models of B2U. The nature of second-life batteries, which is used products, suggests that there are risks for customers to take. As analyzed in section 4.3, customers bear the risks in battery performance, supply as well as contracts. It would be very difficult for second-life batteries to compete with new batteries under product-based, "business-as-usual" scenarios, therefore, innovative business models that provide services rather than sell products are more likely to reduce risks for customers and make second-life batteries more attractive.

\subsubsection{Joint efforts from authorities to demonstrate and educate customers}

The risks around $\mathrm{B} 2 \mathrm{U}$ for customer are mainly due to the absence of standards and customers' poor understanding of second-life batteries. To alleviate customers' concerns about second-life batteries, major OEMs should work actively with the government and research institutions to demonstrate and publicize second-life batteries, leveraging the power of authorities that could help assure customers and make second-life batteries more acceptable.

\subsection{Limitations}

This research aims to provide insights into the market development of second-life EV batteries for both industrial players and policy makers. Through case studies with four representative stakeholders, some initial findings were observed regarding determining factors for B2U and recommendations for stakeholders were proposed. However, this study has several limitations. Firstly, due to limited battery volume and economic uncertainty of battery secondary use, the practice of B2U is still rare. Most of the practices were non-market behaviours for demonstration purposes. This limitation suggests the limited data availability and generalizability of our findings. Secondly, the study has limitation in identifying all the key stakeholders in this emerging industry over a relatively short time period. Also, this paper is only a part of an on-going project and doesn't include the European market, which is one of the most important regions to investigate. To mitigate these limitations, the authors decide to conduct deeper case studies in the existing stakeholders and identify potential key players in the B2U ecosystem. And future studies will include the European market to investigate and understand the B2U market more comprehensively. 


\section{Conclusion}

In summary, this paper has investigated the determining factors for B2U and their influence on shaping the B2U ecosystem. From case studies with major players in the current B2U ecosystem, we observed that a standardized platform, inter-industrial collaboration and regulatory support are the most critical factors for the success of $\mathrm{B} 2 \mathrm{U}$ in the early stage. The competition from new batteries constitutes a major challenge for B2U, which makes it crucial to establish the market and infrastructure for second-life batteries in the near term. The EV manufacturer is the key player in developing the B2U market in the nascent stage. Innovative business models that reduce B2U risks for customers are essential for second-life batteries to compete in the energy storage market. This research has significant practical implications for industrial players to evaluate their own capabilities and relationships with other ecosystem players and for policy makers to reflect on the policies and regulations for the upcoming market of second-life batteries.

\section{References}

[1] IEA, Global EV Outlook: Understanding the Electric Vehicle Landscape to 2020, 2013.

[2] V. V Viswanathan, M. Kintner-meyer, Second use of transportation batteries: Maximizing the value of batteries for transportation and grid services, IEEE Trans. Veh. Technol. 60 (2011) 2963-2970.

[3] E. Cready, J. Lippert, J. Pihl, I. Weinstock, P. Symons, Technical and Economic Feasibility of Applying Used EV Batteries in Stationary Applications, ISBN SAND2002-4084, 2003.

[4] S.J. Tong, A. Same, M. a. Kootstra, J.W. Park, Off-grid photovoltaic vehicle charge using second life lithium batteries: An experimental and numerical investigation, Appl. Energy. 104 (2013) 740-750.

[5] J.S. Neubauer, A. Pesaran, B. Williams, M. Ferry, E. Jim, A Techno-Economic Analysis of PEV Battery Second Use: Repurposed-Battery Selling Price and Commercial and Industrial End-User Value, 2012.

[6] R. Faria, P. Marques, R. Garcia, P. Moura, F. Freire, J. Delgado, et al., Primary and secondary use of electric mobility batteries from a life cycle perspective, J. Power Sources. 262 (2014) 169-177.

[7] C. Heymans, S.B. Walker, S.B. Young, M. Fowler, Economic analysis of second use electric vehicle batteries for residential energy storage and load-levelling, Energy Policy. 71 (2014) 22-30.

[8] I.A.N.L. Argonne, Electric vehicle battery 2nd use study, 1998.

[9] J. Neubauer, K. Smith, E. Wood, A. Pesaran, Identifying and Overcoming Critical Barriers to Widespread Second Use of PEV Batteries, 2015.

[10] P. Wolfs, An economic assessment of "second use" lithium-ion batteries for grid support, in: Univ. Power Eng. Conf. (AUPEC), 20th Australas. IEEE, 2010.

[11] M.R. Starke, G. Andrews, Final Report Economic Analysis of Deploying Used Batteries in Power Systems, 2011.

[12] S. Beer, T. Gómez, S. Member, D. Dallinger, I. Momber, C. Marnay, et al., An economic analysis of used electric vehicle batteries integrated into commercial building microgrids, in: Smart Grid, IEEE Trans., 2012 : pp. 517-525.

[13] W.-C. Lih, J.-H. Yen, F.-H. Shieh, Y.-M. Liao, Second Use of Retired Lithium-ion Battery Packs from Electric Vehicles: Technological Challenges, Cost Analysis and Optimal Business Model, 2012 Int. Symp. Comput. Consum. Control. (2012) 381-384.

[14] N.A. Warner, Secondary Life of Automotive Lithium Ion Batteries : An Aging and Economic Analysis, (2013).

[15] E.N. Elkind, Reuse and Repower: How to Save Money and Clean the Grid with Second-Life Electric Vehicle Batteries, 2014. https://www.law.berkeley.edu/files/ccelp/Reuse_and_Repower_--_Web_Copy.pdf.

[16] M. Foster, P. Isely, C.R. Standridge, M.M. Hasan, Feasibility assessment of remanufacturing, repurposing, and recycling of end of vehicle application lithium-ion batteries, J. Ind. Eng. Manag. 7 (2014) 698-715.

[17] J. Neubauer, A. Pesaran, The ability of battery second use strategies to impact plug-in electric vehicle prices and serve utility energy storage applications, J. Power Sources. 196 (2011) 10351-10358.

[18] Keeli, R.K. Sharma, Optimal use of second life battery for peak load management and improving the life of the battery, 2012 IEEE Int. Electr. Veh. Conf. (2012) 1-6. 
[19] L. Ahmadi, A. Yip, M. Fowler, S.B. Young, R. a. Fraser, Environmental feasibility of re-use of electric vehicle batteries, Sustain. Energy Technol. Assessments. 6 (2014) 64-74.

[20] M. Bowler, Battery second use : A framework for evaluating the combination of two value chains, 2014.

[21] R.K. Yin, Case study research: Design and methods (5th edition), Sage publications, 2013.

[22] M. Valentine-Urbschat, W. Bernhart, Powertrain 2020-The Future Drives Electric, 2009. http://www.rolandberger.at/media/pdf/Roland_Berger_Powertrain_2020_20110215.pdf.

[23] METI, Enhancement of the initiatives concerning the promotion of electric and other vehicles, http://www.meti.go.jp/english/press/2015/0312_02.html.

\section{Authors}

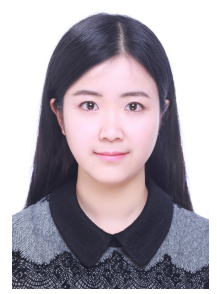

$\mathrm{Na}$ Jiao is a $\mathrm{PhD}$ candidate at the University of Cambridge, Institute for Manufacturing. Her project is on business models for sustainability and business ecosystem in the electric vehicle industry. With a special interest in the secondary use of electric vehicle batteries, her research focuses on the ecosystem emergence of battery second use and how innovative business models influence the development of the ecosystem.

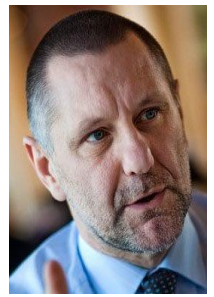

Steve Evans is the Director of Research in Industrial Sustainability and a Professor at the University of Cambridge, Institute for Manufacturing. His research seeks a deep understanding of how industry develops solutions that move us towards a sustainable future. His leading research programmes include sale-of-service business models, eco-design, adoption of novel environmental technologies and integration of lean and environmental programmes. 